Journal of Engineering Science and Technology Review 7 (5) (2014) 47- 50

Special Issue on Simulation of Manufacturing Technologies
JOURNAL OF

Engineering Science and

Technology Review

Conference Article

\title{
Theoretical and experimental stress-strain analysis of machining gas turbine engine parts, which made of the high energy structural efficiency alloys
}

\author{
V. V. Postnov, S. V. Starovoitov", S. Y. Fomin and R. R. Basharov \\ Dept. of Mechatronic Machining Systems, Ufa State Aviation Technical University, Ufa, 450000, Russia
}

Received 10 September 2014; Accepted 27 September 2014

\begin{abstract}
Methods to improve accuracy of the gas turbine engine (GTE) blades machining by analyzing the stress-strain state were reviewed. The new method to compensate for machining error was proposed. The model of parameters that affect cutting mode and the radial component of cutting force during milling was developed.
\end{abstract}

Keywords: blisk, blade, elastic displacements, compensation, radial component of cutting force.

\section{Introduction}

Technological improvements in the field of machining blades for gas turbine engines (GTE) must be towards increasing economic efficiency: improve the material resources utilization rate, reduce labor and the technology development cost.

The modern Russian aircraft engine industry has been undergoing significant changes in recent years in relation to the development of the next generation of GTE. In addition to using new materials, there have been improvements in the design of parts and assembly units. Many GTE assembly units are manufactured as a single part to reduce weight, increase rigidity and improve the reliability and durability. High pressure turbine blisks are an example. However, the stock material utilization rate is not satisfactory when one has to machine parts from solid blocks. So instead welding blades on disk is used.

The blade has a low rigidity as a part itself. So the cutting force applied produces an elastic displacement error during machining. Specialized fixtures to rigidly fix the machined surface increases setup time. This also results in additional costs for designing and manufacturing fixtures. This approach especially increases weld blisk machining costs when it is necessary to machine a set of blades in one setup.

In this article a new method to improve the accuracy by taking into account the elastic deformation error from the cutting force during the blade machining is proposed.

\section{Estimation of the error of welded blisk blade during machining}

The blade on a welded blisk is formed by transverse rows end milling. The milling cutter moves in the $\mathrm{X}$ and $\mathrm{Y}$ axes with feed $\mathrm{S}$ and at a different angle to the machining surface.

\footnotetext{
*E-mail address: sv_starov@mail.ru

ISSN: 1791-2377 (C) 2014 Kavala Institute of Technology. All rights reserved.
}

An estimation scheme is made to ensure the geometric

accuracy of the blade (Fig. 1).

According to the estimation scheme (Fig. 1), the blade is considered as a bending and twisting elastic cantilevered beam. The blade part of a part in the $\mathrm{X}$ and $\mathrm{Y}$ axes has significantly different moments of inertia $J_{X}$ and $J_{Y}$, which are $J_{X} \gg J_{Y}$. Therefore strain in the direction $Y\left(\delta_{Y}\right)$ is greater than in $X\left(\delta_{X}\right)$, i.e. $\delta_{Y}>>\delta_{X}$.

This allows to neglect circumferential and lateral components of the cutting force when the blade machining error is estimated. Later in the analysis only the radial component of the cutting force is taken into account. It is indicated on the estimation scheme as $P_{i j}$ and defined by the Eq. 1.

$P_{i j}=0,5 \cdot C_{P} \cdot v_{i}^{x} \cdot S_{i}^{y}$,
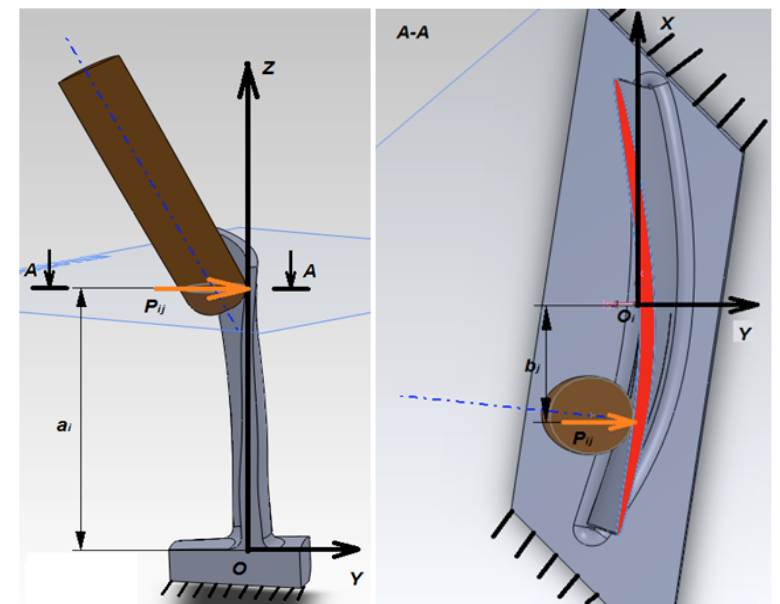

Fig. 1. Estimation scheme to ensure geometric accuracy of the blade during welded blisk machining 
where $C_{P}, x, y-$ are experimentally determined cutting force power function coefficients of speed and feed.

$$
\text { It takes } \quad x=0,15 \ldots 0,2 ; \quad y=0.65 \ldots 0,7 \text {; }
$$

$C_{P}=(3,1 \ldots 3,4) \cdot 10^{4}$ for milling titanium alloys [1].

Thus, the blade displacement from bending in the direction Y can be determined by Eq. 2 [2]:

$$
\delta_{Y}=\frac{P_{i j} \cdot a_{i}^{3}}{3 \cdot E \cdot J_{X}}
$$

where $P_{i j}$ - radial cutting force in $i$-th section in the $j$-th position from the mass center of this section;

$a_{i}$ - height of the $i$-th machining section from the base of the blade;

$E$ - blade material Young's modulus. $E=100 \mathrm{GPa}$ for titanium alloys [2];

$J_{X}$ - blade section first moment of area relative axis $X$.

The blade displacement from twisting in the direction $\mathrm{Y}$ can be estimatd with Eq. 3 [1]:

$\delta_{t w}=\frac{P_{i j} \cdot b_{j}^{2} \cdot a_{i}}{G \cdot J_{p}}$

where $b_{j}$ - distance from the milling cutter in the $j$-th position along the $\mathrm{X}$ axis to the section's $i$-th mass center; $G$ - blade material shear modulus. $G=40 \mathrm{GPa}$ for titanium alloys [2];

$J_{p}$ - blade section second moment of area.

Total displacement at the blade machining point in the direction $\mathrm{Y}$ can be determined by Eq.4.

$$
\delta=\delta_{Y}+\delta_{t w}=\frac{P_{i j} \cdot\left\lfloor G \cdot J_{p} \cdot a_{i}^{3}+3 \cdot E \cdot J_{X} \cdot b_{j}^{2} \cdot a_{i}\right\rfloor}{3 \cdot E \cdot G \cdot J_{X} \cdot J_{p}} .
$$

The blade elastic displacements during milling lead to machined profile errors. So the value of this error is different at various points. It is possible to compensate for this machining error if the NC-file is corrected appropriately.

There are 2 methods to reduce machining error by NCfile correction:

1. To change cutting mode during machining compliance with $\delta \leq K \cdot T_{o p}$, where $K=0,3 \ldots 0,7$ - tolerance utilization rate; $T_{o p}$ - tolerance on operation size [1];

2. To change the toolpath by the amount and direction of the blade elastic displacements.

3. Method for compensating for blade elastic displacements compensation with the toolpath correction

It is effective to compensate for the workpiece elastic displacements with the toolpath correction, when it is necessary to setup the machine for one type of blade production quickly. Blade machining at a constant feed and speed produces stable surface roughness and it makes possible to choose the optimum cutting mode and maximize tool life.

The usual cutting parameters for a titanium alloy compressor blade milling is: tool speed $v \geq 120 \mathrm{~m} / \mathrm{min}$; feed $S \leq 1000 \mathrm{~mm} / \mathrm{min}$; cutting depth $t$ at rough cutting $0,4 \ldots 0,5 \mathrm{~mm}$, semifinishing $0,2 \ldots 0,3 \mathrm{~mm}$, finishing 0,1 $\mathrm{mm}[1]$.

The method is as follows:

1. Initial blade machining at the pre-selected constant cutting mode.

2. Machined surface measurement and evaluation of error;

3. Building a corrected solid model of the blade. Profile points at each blade section must be displaced by an amount of error to the initial profile;

4. Building a new NC-file based on the corrected solid model with CAM.

The machined surface is measured by a probe. The measured NC-file is built by a CAI-system. Measurement data together with the initial solid model are used to build a corrected solid model with CAD. The new solid model is used by CAM to built the new NC-file.

The steps above are repeated several times to provide the desired geometric blade accuracy after an initial workpiece machining with the new NC-file. Then a set of blades is machined with the NC-file, which was built for the last corrected solid model.

This method achieves the required machined surface geometric accuracy in a short time and with minimal effort.

However, this method has to be repeated every time when a setup for new types of blades machining is needed or when different tools are used.

\section{Testing the method of compensating for blade elastic displacements}

For testing this method rectangular plates of titanium alloy VT6 GOST 19807-91 end milling was used. The plate dimensions were selected so, that the geometric characteristics, which determine rigidity, are similar to the GTE compressor blade geometric characteristics.

Plate climb milling was performed in the machining center MTE 500V5. A milling cutter Sandvik CoroMill 390 $\varnothing 20 \mathrm{~mm}$ with 3 cutting inserts, side cutting edge angle $\varphi=90^{\circ}$, rake angle $\gamma=0^{\circ}$, clearance angle $\alpha=21^{\circ}$ and nose radius $r=1,6 \mathrm{~mm}$ was used. Measurement was carried out by NC for 10 points. The machining center MTE 500V5 is equipped with a measuring probe Renishaw MP10 and optical input-output device Renishaw OMM, which was used for measurement. The measurement data were recorded in CNC R-parameters.

The mathematical model of the effect cutting mode parameters have on the radial component of the cutting force was defined. Using the procedure described in [3] experimental design was used (Table 1). A reduced experimental set $2^{3}$ was performed. Levels and varying intervals for input variables were selected according to the Sandvik Coromant cutting mode recommendation for titanium alloys milling. The input variables were cutting speed, feed rate and width of cut. Taking into account the measuring probe diameter the depth of cut was set to $3 \mathrm{~mm}$. The output variable was the radial component of the cutting 
force. This was determined indirectly from Eq. 4 by measuring data for 10 checkpoints with known overhangs $b_{j}$ and $a_{i}=13,5 \mathrm{~mm}$.

Table 1. Levels and varying intervals for variable factors

\begin{tabular}{|c|c|c|c|c|c|c|}
\hline Input variable & Factor & -1 & $\mathbf{0}$ & 1 & $\begin{array}{c}\text { Inter } \\
\text { val }\end{array}$ & $\begin{array}{c}\text { Dimensi } \\
\text { on }\end{array}$ \\
\hline Cutting speed $\mathbf{v}$ & $\mathbf{X} 1$ & 50 & 100 & $\begin{array}{c}15 \\
0\end{array}$ & 50 & $\mathbf{m} / \mathbf{m i n}$ \\
\hline Feed rate $\mathbf{S}$ & $\mathbf{X} 2$ & 0,1 & 0,15 & 0,2 & 0,05 & $\underset{\text { th }}{\mathrm{mm} / \mathrm{too}}$ \\
\hline Width of cut $\mathbf{w}$ & $\mathbf{X 3}$ & 0,5 & 0,75 & 1 & 0,25 & $\mathbf{m m}$ \\
\hline
\end{tabular}

As a result, Eq. 5 was obtained.

$P=5494,61 \cdot v^{-0,186} \cdot S^{0,249} \cdot w^{1,924}$,

The parameters that affect the radial component of the cutting force based on Eq. 5 are shown in Fig. 2. This figure shows, that with increasing cutting speed the radial component of the cutting force decreases. But the radial component of the cutting force increases with feed rate and width of cut. And it is more sensitive to the increase of the width of cut.

The stock to be removed was measured before each cutting pass with the selected cutting mode. The measurement data were used for the checkpoints selection with the same stock. The mathematical model of the influence of the cutting mode parameters have on radial component of the cutting force was formulated with these checkpoints. The first pass with the specified cutting mode was performed using the default NC-file along the initial profile, which was defined by 4 pivot points. Then a profile error measurement was performed. These data were used to correct the NC-file. The corrected NC-file toolpath was based on 10 checkpoints as it presented at cut-map (Fig. 3).

Changing from the initial NC-file the new corrected NC-file checkpoints coordinate $\mathrm{X}$ was defined by Eq. 6 according to the cut-map in Fig. 3.

$$
T_{i}(X)=\left\{\begin{array}{c}
0-\Delta_{R i}, 1 \leq i \leq 5 \\
-A+\Delta_{R i}, 6 \leq i \leq 10
\end{array}\right.
$$

Then the second pass was performed with the correct $\mathrm{NC}$-file and 10 checkpoints were measured again. After machining with the corrected NC-file a new workpiece was prepared. The stock to be removed was measured again for the new workpiece. Then a third pass with the specified cutting mode was performed directly with the corrected NC-file. After that the 10 checkpoints were measured again

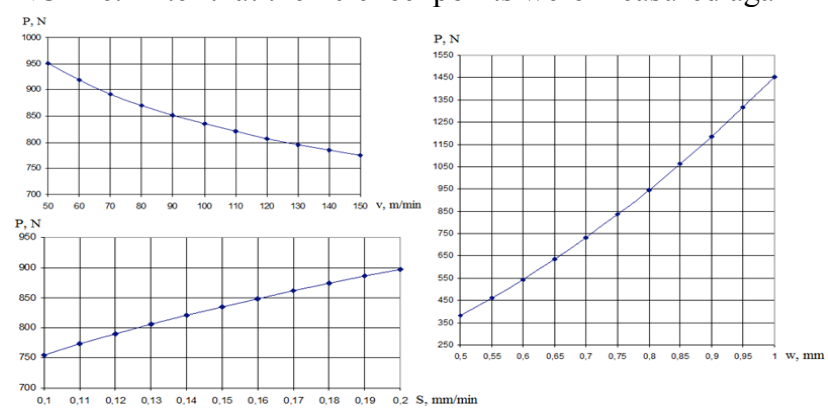

Fig. 2. Effect of cutting speed (v), feed rate (S) and width of cut (w) on the radial component of the cutting force P during titanium alloy VT6 GOST 19807-91 end milling with a milling cutter $\varnothing 20 \mathrm{~mm}$ with inserts $\mathrm{S} 30 \mathrm{~T}(S=0,15 \mathrm{~mm} /$ tooth, $w=0,75 \mathrm{~mm})$
Fig. 3. A corrected NC-file cut-map
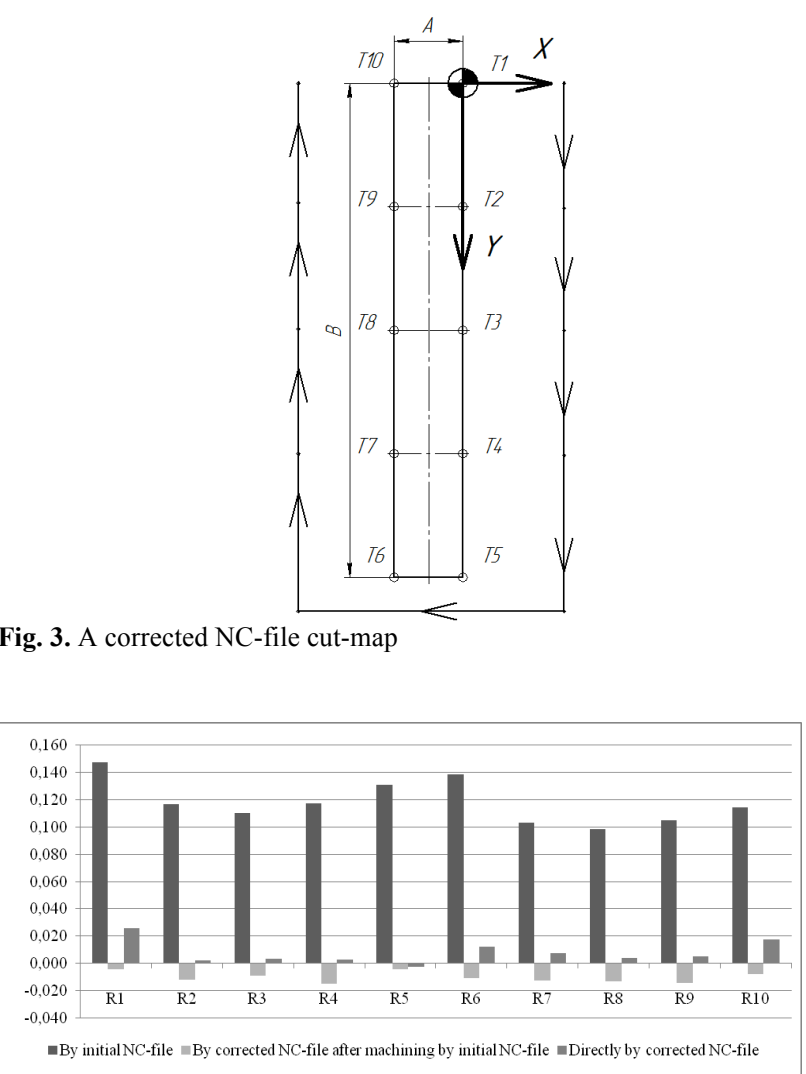

Fig. 4. Comparative histogram of checkpoint error average values during machining with tested cutting modes

to compare the error between the initial and the corrected NC-file.

The profile error average values for all tested cutting modes when machining with the initial NC-file, with the corrected NC-file after machining with the initial NC-file and directly with the corrected NC-file in the histogram are shown in Fig. 4. This shows the machining accuracy improvement with the method of compensating for the elastic displacements.

\section{Conclusions}

The proposed method of compensating for blade elastic displacements allowed to reduce the machining error with the tried cutting modes from 102-175 $\mu \mathrm{m}$ to $1-35 \mu \mathrm{m}$. Therefore it is possible to improve the blade machining accuracy significantly by using this method. It is necessary to measure at the beginning the machined blade and correct the NC-file during the welded blisk machining.

Using experimental data the model of the parameters that affect the cutting mode radial component of cutting force was constructed using the design of experiments method. This model is adequate for the titanium alloy VT6 GOST 19807-91 end milling with a milling cutter Sandvik CoroMill $390 \varnothing 20 \mathrm{~mm}$ having inserts S30T.

The theoretical and experimental stress-strain analysis of the GTE blade during milling revealed, that it is possible to minimize workpiece bend and to improve machining accuracy. Control of the radial component of the cutting force can be achieved and produce a corrected NC-file, which based on the toolpath correction taking into account the workpiece rigidity. 
V. V. Postnov, S. V. Starovoitov, S. Y. Fomin and R. R. Basharov/Journal of Engineering Science and Technology Review 7 (5) (2014) 47 - 50

\section{References}

[1] Poletaev, V., A. Technology of machine aided gas turbine engine blades production, Moscow: «Machine buillding», 2006. - $256 \mathrm{p}$. (in Russian)

[2] Zhernakov, V., S., Gafarov, R., K. What are important to know about structural performance of materials, Study guide under the editorship V. S. Zhernakov, Moscow: «Machine buillding», 2001. 276 p. (in Russian)

[3] Makarov, A., D., Krivoshey, V., M., Nikitin U., V. The application of mathematical experiment planning for the base metal cutting process parameters research, Study guide, Ufa: Publishers of Ufa Aviation Institute named after Ordzhonikidze, 1976. - 116 p. (in Russian) 